\title{
Formação de professores e prática pedagógica na perspectiva freireana
}

\section{Teacher development and pedagogical practice in the light of Freire}

\author{
Eliete Santiago ${ }^{1}$ \\ José Batista Neto ${ }^{1}$
}

\begin{abstract}
RESUMO
O artigo aborda as contribuições de Paulo Freire para a formação de professores/as e a prática pedagógica a partir da categoria diálogo. A prática pedagógica ganha centralidade como categoria de análise e como atividade formadora, tratada numa perspectiva institucional e plural, enquanto que a prática pedagógica docente se constitui em uma das suas traduções. A dimensão relacional é destacada como característica e base do pensamento freireano, bem como explicação das relações ensino-pesquisa, docência-discência, sujeitos da educação-contexto socioeducacional.
\end{abstract}

Palavras-chave: formação de professores; prática pedagógica; diálogo.

\begin{abstract}
This article discusses Paulo Freire's contributions to teacher development and pedagogical practice from the perspective of the dialogue category. Pedagogical practice is the core as an analysis category and a development activity which is treated on an institutional and pluralized perspective while pedagogical practice constitutes itself in one of its translations. The relational dimension is highlighted as characteristic and basis of Freire's thoughts as well as the explanation of the relation teaching-research; teaching-learning; learners-socio-educational context.
\end{abstract}

Keywords: teacher development; pedagogical practice; dialogue.

DOI: $10.1590 / 0104-4060.47202$

1 Universidade Federal de Pernambuco. Programa de Pós-Graduação em Educação. Recife, Pernambuco, Brasil. Av. Prof. Moraes Rêgo, no 1.235. Cidade Universitária. CEP: 50.670-901. E-mails: mesantiago@uol.com.br e josebn@uol.com.br 


\section{Palavras iniciais}

Nos campos da educação e da escolarização, a instituição escolar ganha centralidade em função da sua responsabilidade histórica pela apropriação e socialização do saber produzido pela humanidade. Políticas são formuladas, tendências são descritas e críticas são dirigidas às formas de organização, seu funcionamento e seus resultados. Porém, se parece haver um consenso é quanto à relevância social da escola, entendida como um espaço de materialização do direito à educação e, consequentemente, de efetivação das políticas educativas.

Em que pese a importância da escola e a disputa, na sociedade, por um projeto educativo que lhe imprima sentido e significado, nem sempre ela responderia aos requerimentos da população escolar, seja de forma quantitativa ou qualitativa, haja vista suas condições para a garantia da oferta, bem como os déficits e os resultados que as estatísticas educacionais apontam e as práticas que ela desenvolve ou aquelas que poderia desenvolver com o fito de ampliar e consolidar direitos sociais e justiça curricular.

O discurso da educação de qualidade e a luta pela sua garantia nem sempre vêm acompanhados das condições fundamentais para que se dê materialidade a políticas educativas, por razões de natureza ética, pedagógica ou material. Ou seja, discurso, política e prática pedagógica nem sempre guardam coerência, afastando-se, muitas vezes, das intenções proclamadas. Isto pode ser conferido, por exemplo, nas reações de certos setores e segmentos sociais à implantação de normativa da valorização do magistério, como o piso salarial nacional dos professores. Pode ser conferido também na presença de currículos apostilados, nos sistemas de ensino e na escola, bem como em políticas de formação de professores/as, que se fazem por meio de programas aligeirados e precários em suas condições de oferta. Não resta dúvida que tudo isso tem repercussão para o funcionamento da escola básica.

Neste artigo, a preocupação se volta para a contribuição dos referenciais freireanos para a prática pedagógica e para o processo crítico formativo, visto que eles carregam a possibilidade de contribuir para a análise dessas questões e, possivelmente, intervir no trabalho educativo escolar. Nosso ponto de partida é a aproximação entre prática pedagógica e formação docente, seguida da abordagem do diálogo, tomado como categoria teórica e atitude pedagógica, na perspectiva freireana, e que se conclui ao pôr em evidência a contribuição de Paulo Freire para o trabalho docente-discente na escola, reafirmando, através de pesquisas recentes, que o pensamento do educador pernambucano pode subsidiar o que fazer docente na escola básica. 


\section{Referenciais freireanos presentes na prática pedagógica de professores/as e formação permanente}

A formação permanente inscreve-se na natureza inconclusa do ser humano, na infinitude do conhecimento e na dinâmica das relações sociais. Portanto, não se restringe e nem se confunde com as modalidades da formação inicial e continuada, embora as incorpore. Ela se realiza, preponderantemente, através da reflexão sobre a prática. (FREIRE, 1985, 1997, 2006). Assim, formação e prática pedagógica, embora guardem especificidades, uma não existe sem a outra e, em relação, instauram a formação permanente.

Essa formulação teórica está no conjunto da obra de Paulo Freire, sustentada por categorias analíticas, princípios, ação e reflexão, entre as quais destacamos o diálogo como contribuição teórica, metodológica e postura pedagógica, uma vez que o diálogo é fundamento da educação problematizadora e exigência existencial da natureza do homem e da mulher.

As contribuições de Paulo Freire, na perspectiva da teoria dialógica, para o processo formativo de profissionais que atuam ou atuarão na escola básica têm sustentação nas concepções de ser humano/homem-mulher, mundo/cultura e conhecimento, assim como nas relações que são desencadeadas entre si. Essas concepções e relações são fundamentos indispensáveis para situar e analisar o lugar social e pedagógico do/da docente-discente na escola. Essas bases explicitam princípios, finalidades e posturas do ser professor/a e ser estudante e, ao mesmo tempo, constituem conteúdo da formação de sujeitos críticos e criativos, cujos referenciais Paulo Freire oferece.

Nessa perspectiva teórica, homem/mulher são sujeitos da história, da educação e do conhecimento implicando na sua participação efetiva em todo o processo educativo, seja ele escolar ou realizado através dos movimentos sociais. No campo da educação, professores/professoras são sujeitos que vivem, movem-se e atuam em espaços sociais diversos, mas a escola é, particularmente, o lócus privilegiado da atuação docente-discente. Dito de outro modo, professores/as são profissionais que trabalham com o conhecimento e com pessoas e, nessa relação, o diálogo ganha configuração de princípio e atitude pedagógica mediando sujeito e contexto socioculturais.

O diálogo, essa dimensão relacional e dinâmica do pensamento freireano, é fundamento da ação pedagógica, é mediação entre sujeito e realidade, realiza-se como discurso e prática de compreensão e de intervenção na realidade. Ele traduz a natureza do ser humano/homem-mulher e, no dizer de Paulo Freire, 
[...] como fenômeno humano, se nos revela algo que já podemos dizer ser ele mesmo: a palavra. Mas, ao encontrarmos a palavra, na análise do diálogo, como algo mais que um meio para que ele se faça, se nos impõe buscar, também, seus elementos constitutivos. (FREIRE, 2009, p. 89 , grifo no original).

O autor mostra que ação e reflexão são dimensões da palavra que, solidariamente, compõe o diálogo, ao mesmo tempo em que afirma não haver "[...] palavra verdadeira que não seja práxis. Daí que dizer a palavra verdadeira seja transformar o mundo". (FREIRE, 2009, p. 89).

Nessa direção, a palavra verdadeira ou autêntica, cujo sentido próprio incorpora a noção de direito à ação coletiva de intervenção sobre algo em um dado contexto, se inscreve como diferenciação de verbalismo. Por isso o autor assim se refere:

A palavra verdadeira, que é trabalho, que é práxis, é transformar o mundo, dizer a palavra não é privilégio de alguns homens [e mulheres], mas direito de todos os homens [mulheres]. Precisamente por isto, ninguém pode dizer a palavra verdadeira sozinho, ou dizê-la para os outros, num ato de prescrição, com o qual rouba a palavra aos demais. (FREIRE, 2009, p. 90-91).

Visto desse modo, a palavra como constitutiva do diálogo também pode ser considerada, quando autêntica, o diálogo propriamente dito. É a pronúncia do mundo. O seu fundamento é a concepção de homem/mulher, de educação e de conhecimento compreendidos e atuando como sujeitos históricos que têm, na educação, um instrumento de compreensão da realidade sócio-histórico-político-cultural-pedagógica.

A matriz do diálogo é formada por um conjunto de princípios que traduzem a relação de objetividade-subjetividade, cuja mediação é feita pelos contextos de vida e saberes praticados dos sujeitos. Parte, portanto, da visão omnilateral de homem/mulher e se funda no amor, na humildade, na fé no homem/mulher, na esperança e no pensar crítico. (FREIRE, 2009). Caracteriza-se como um ato que vai além da fala-escuta. É um processo de fala-escuta, mas perpassado e configurado como pronúncia do mundo-reflexão-ação coletiva.

Essa matriz, com traços e atos objetivo-subjetivos, institui as dimensões utópica, relacional e dinâmica da educação problematizadora. Nela, o amor 
significa compromisso. É comprometer-se, individual e coletivamente, com projetos e causas voltados para o direito, a justiça social e curricular. É também superação da arrogância, da autossuficiência e significa o exercício da humildade como possibilidade humana de criar e recriar, do agir coletivo. É por isso que encontramos nos escritos de Paulo Freire $(2009$, p. 93) que "[...] não há ignorantes absolutos, nem sábios absolutos: há homens [mulheres] que, em comunhão, buscam saber mais".

Em resumo, a busca pelo saber mais é um exercício relacional de humildade, de compromisso com o outro e com o todo na construção da pronúncia do mundo: compreensão e ação em direção à justiça social, por isso requer o conhecimento crítico, que favoreça leituras críticas de mundo.

É essa contribuição freireana para uma prática docente-discente e como processo formativo permanente que buscamos evidenciar, através do exercício do diálogo, no horizonte da humanização dos sujeitos docente-discente no trabalho com crianças, jovens ou adultos.

\section{Contribuição freireana à pratica pedagógica docente-discente}

A materialidade do pensamento freireano ocorre em campos como ensino, pesquisa e extensão, suscitando conhecimentos diversos. É base teórica, referencial metodológico e objeto de ensino e de pesquisa. O estudo de categorias teóricas ocupa espaço amplo para orientar o olhar investigativo para fontes e para o trabalho educativo e também para a atividade docente na escola. Nesse caso, sinaliza para a importância da relação dialógica no horizonte da humanização e da justiça curricular, com ênfase na formação permanente como condição para o fazer e refazer do ciclo do conhecimento, haja vista ser ela a formação "[...] que se funde, sobretudo, na reflexão sobre a prática”. (FREIRE, 2006, p. 25).

A contribuição de Paulo Freire à prática pedagógica tem sido objeto de pesquisas recentes, a exemplo de Braga (2012, 2015), Guedes (2012, 2015), Leitão (2015) e Silva (2016), todas elas desenvolvidas em escolas públicas e abrangendo as etapas da educação infantil, do ensino fundamental e da modalidade de educação de jovens e adultos. Ao aludirmos a esses trabalhos, buscamos colocar em evidência os referenciais freireanos como contribuição à prática pedagógica para a humanização, finalidade da educação problematizadora, cujo foco é o diálogo. Educação problematizadora compreendida como aquela em que os/as educandos/as são chamados/as a conhecer, a realizar o ato cognoscitivo enquanto que o objeto do conhecimento faz a mediação professor/a-estudante. 
Em Paulo Freire (2006, p. 80), essa educação "[...] de caráter autenticamente reflexivo, implica um constante ato de desvelamento da realidade".

Nessa concepção de educação e da finalidade educativa, o diálogo ganha centralidade e a humanização como categoria de análise e horizonte da prática pedagógica docente indica o lugar epistêmico do diálogo. (BRAGA, 2015; GUEDES, 2015; LEITÃO, 2015; SILVA, 2016).

Braga (2015) reconhece a contribuição freireana para o campo do currículo, da formação e da prática docente quando identifica princípios da pedagogia libertadora no trabalho docente-discente e evidencia inspiração nas práticas pedagógicas do movimento da sala de aula, sem isolá-lo da escola na sua globalidade, ao mesmo tempo em que ressalta o exercício do ciclo do conhecimento, ressignificando-o como ciclo de leitura. Aqui, leitura associa-se a contexto para equiparar-se à afirmação de Freire de que a leitura do mundo antecede a leitura da palavra, ainda que sem desprezar esta última.

A pesquisadora destaca a leitura como um instrumento básico da relação docente-discente, analisa-a como situação produzida para o desenvolvimento da criticidade e objeto de criação-recriação do conhecimento. A leitura de textos e contextos são situações organizadas para possibilitar a tematização e propostas de ação, conforme os estágios das crianças. Em síntese, a leitura constitui relação dialógica, mediada pelas experiências docente-discente, bem como é promotora de satisfação. Diz a autora sobre a leitura:

Trabalhada todos os dias e em distintas formas, não para dar conta, apenas, da gramática, da ortografia, mas para fazer a leitura dos contextos em que as crianças viviam, despertando-lhes a alegria de estar na escola, de aprender, e fazer parte da história e da vida da escola: a alegria de ler o mundo, lendo histórias, palavras, enredos, textos literários, músicas, danças, dramatizações, imagens e atitudes. (BRAGA, 2015, p. 292).

O olhar minucioso e a escuta atenta possibilitaram a apreensão da multiplicidade de textos utilizados no dia a dia de crianças e professoras, a diversidade de situações criadas para o incentivo à leitura e à escrita e os sentidos explorados dos textos que declararam que ensinar não é transferir conhecimento. (FREIRE, 1997, p. 52).

A organização da agenda, dispositivo pedagógico, consistiu no exercício formativo e de disciplina intelectual docente-discente e fez parte da cena pedagógica do cotidiano escolar. Possibilitou o exercício da fala e da escuta dos/das estudantes; a tematização da palavra e o respeito ao tempo das aprendizagens e 
das experiências de cada um/uma no conjunto da sala de aula. Refere-se Braga (2015) à construção e ao uso da agenda como baliza da relação docente-discente e conteúdo da palavra - objeto da problematização, da decisão e da efetivação das situações de produção do conhecimento -, como podemos ver nos trechos a seguir:

A agenda não constituía roteiro rígido a ser cumprido, mas uma baliza das ações e relações efetivadas pelas professoras e pelos/as estudantes. Por diversas vezes, diante de argumentos coerentes, as sugestões de alteração, tanto no sentido de postergar uma tarefa ou antecipá-la, foram acatadas, de modo que a agenda era uma forma de organização do trabalho coletivo nas salas de aula. (BRAGA, 2015, p. 160).

A abordagem feita sobre práticas alternativas, como reaproveitamento alimentar, das cascas de frutas e de ovos e outras formas encontradas de produzir menos lixo, foi apresentada pela professora em meio às contribuições dos/das estudantes, bem como o reconhecimento de que a reciclagem do lixo é alternativa para a superação dos problemas causados pela produção dos rejeitos. (BRAGA, 2015, p. 183).

É possível ainda conferir a autonomia docente para as decisões pedagógicas. As atividades de rotina ganham significado no dia a dia de professores/ as e estudantes, ressignificando dispositivos pedagógicos. A prática pedagógica docente-discente é refletida e incorpora-se como formação permanente do/da docente.

$\mathrm{Na}$ investigação conduzida por Leitão (2015), o diálogo constitui conteúdo e forma das vivências da Educação de Jovens e Adultos (EJA). Nesta modalidade, ganharam destaque as situações de ensino e, nessas, as produções escritas resultantes de temas e materiais diversos de leitura. $\mathrm{O}$ procedimento básico investigativo foi a observação de contextos sociocultural/pedagógico dos/das professores/as e estudantes que possibilitaram relatos de experiências e situações observadas e/ou vivenciadas que, problematizadas, foram objeto de sistematização em sala de aula. Destaca-se a discussão de temas, como acessibilidade, gênero, questões ambientais, gerados, por vezes, a partir das histórias de vida dos/das estudantes.

No conjunto das atividades, a redação de cartas serve como síntese ilustrativa do esforço político-pedagógico docente para a materialidade de princípios 
freireanos. Nela é possível identificar a experiência de leitura da realidade, mobilização de ideias, saberes, ações e incentivo à participação social.

Trata-se de uma atividade que inicia pela indagação sobre "as principais dificuldades enfrentadas pela população" no seu bairro (LEITÃO, 2015, p. 97), a mesma comunidade em que a escola se localiza. O lixo ocupou espaço central nas discussões: causas, consequências, responsabilidades - a denúncia. A discussão, com a mediação docente, evoluiu para a busca de soluções. Várias possibilidades surgiram e, entre outras, estava a carta para o vereador eleito pela comunidade que recebeu a adesão do grupo e da docente que passou à construção coletiva e orientação para fazer a carta chegar ao seu destinatário. (LEITÃO, 2015, p. 98). Portanto, a proposta metodológica do diálogo freireano é traduzida em estratégia didático-pedagógica, que possibilitou: leitura da realidade - problematização - análise e proposta de ação, não como uma técnica de redação - embora a preocupação estivesse presente - mas como tradução de uma concepção de educação que tem como finalidade a compreensão e a intervenção na realidade.

Nesse sentido, Leitão (2015, p. 104) ressalta que “[...] os conteúdos de ensino, não são propriedades do(a) professora, por isso não podem ser impostos, mas objeto de reflexão de todos(as) que, em cooperação, participam do processo de aquisição do conhecimento".

Não resta dúvida que uma atividade curricular como esta, que ocupou várias aulas e constituiu relações diversas (docente-discente, escola-comunidade), não ocorre sob o controle dos relógios ou das propostas externas que negam a autonomia docente. Exige vários encontros pedagógicos (aulas) para atingir a sua finalidade didático-político-pedagógica. Ocorre, portanto, em um tempo curricular que, antes de tudo, é um tempo de confiança no outro e de compromisso com o outro, traduzido pela seleção de conteúdos, de materiais e de práticas propiciadoras do conhecimento crítico. Exige, pois, a opção política do/ da docente e uma base de conhecimento - formação permanente, bem como a intencionalidade da prática pedagógica intencional (SOUZA, 2009), que respalde a prática docente-discente.

A perspectiva dialógica na EJAé mostrada sob diferentes aspectos: a leitura de mundo a partir de atividades e experiências que possibilitam a discussão e a apreensão da realidade; o respeito aos ritmos de aprendizagens dos/das estudantes traduzidos no tirar dúvidas, incentivar a capacidade de realização de atividades; a amorosidade vista no clima de confiança, zelo pela aprendizagem e cuidado com o ambiente escolar, além da presença efetiva das professoras na sua jornada de trabalho.

Podemos observar uma síntese da dimensão relacional, dinâmica e dialógica no trecho a seguir com destaques para a condição de sujeitos dos/das 
estudantes, para a perspectiva crítica do conhecimento, a crença nos sujeitos e os temas da realidade como conteúdo programático.

\begin{abstract}
A prática pedagógica docente não se limitou a uma visão de escrita onde os(as) estudantes organizassem palavras e frases prontas para produzir um texto. Mas buscou provocar a turma para que fossem produtores ativos na construção do conhecimento, expressando o resultado das interações construídas com o grupo. Essa atitude favoreceu a produção crítica e criativa como no texto produzido pela estudante a qual evidenciou a compreensão sobre a temática da acessibilidade e os paradoxos do cenário político, que interferem na ausência de compromisso com os problemas de mobilidade enfrentados no cotidiano das pessoas. (LEITÃO, 2015, p. 102).
\end{abstract}

Nesta pesquisa, a formação ocorreu em diferentes espaços e formas, podendo ser observada na reflexão e nos encaminhamentos que a prática pedagógica docente-discente exigia e nos processos formativos institucionais, instalados em formato de atividades, como a Semana Cultural da EJA e o acompanhamento e o estudo na instância municipal de coordenação de EJA.

A prática pedagógica, na perspectiva dialógica, constituiu um achado da pesquisa desenvolvida por Guedes $(2012,2015)$, cujo campo de investigação foi, desta feita, a educação infantil. Sistematicidade do processo formativo, reflexão sobre a prática e socialização de experiências caracterizam a formação dos/as professores/as da educação infantil e a prática pedagógica docente-discente. Assim registra a pesquisadora:

Os encontros quinzenais nas escolas possibilitaram aos(às) professores(as), em articulação com a equipe pedagógica, oportunidades de socializar experiências no coletivo; refletir sobre suas práticas; dialogar sobre as diferentes questões que envolviam o cotidiano escolar; realizar estudos para fundamentar tais discussões. A equipe pedagógica se fazia presente nas escolas, a fim de acompanhar a repercussão dos estudos realizados no processo de formação no trabalho docente, nas unidades escolares, bem como de contribuir com referenciais teóricos sobre as questões escolares e de ensino que surgissem. (GUEDES, 2015, p. 277).

A relação dialógica na educação infantil é apreendida por Guedes (2012, 2015) a partir de um conjunto de situações organizadas para a produção do 
conhecimento, de espaço e tempo curriculares, atividades docentes-discentes, entre as quais estão a roda de conversa, a contação de histórias, as brincadeiras, a análise linguística e a produção artística.

A própria organização do espaço de sala de aula constitui experiência curricular, educativa e dialógica. A mobilização dos espaços de aprendizagens, como espaço dinâmico e dialógico para o trabalho com as crianças da educação infantil, foi sendo construída a partir da relação estabelecida entre docente-discente; discente-discente, docente-conhecimento-discente, mediada pelos relatos de casos, contos e histórias infantis, criadas, contadas, lidas e desenhadas. Isto é, a mediação se fez com linguagens e leituras da realidade pelas lentes do olhar infantil.

A pergunta ganhou espaço na relação docente-discente como curiosidade espontânea ou direcionada. $\mathrm{O}$ incentivo à participação nas atividades propostas e selecionadas fez-se com frequência, observando-se o respeito aos interesses, tempos e ritmos das crianças.

O diálogo como conteúdo da prática pedagógica também é apontado por Guedes (2015). Na sua construção, a amorosidade perpassa e institui a rotina na educação infantil, traduzida como bem querer, rigorosidade, disciplina intelectual, uso do tempo curricular, trato com o conhecimento e compromisso com o protagonismo infantil.

A amorosidade é destacada ainda na relação docente-conhecimento-discente como um princípio pedagógico que orienta o trabalho educativo na educação infantil e se mostra como atitude pedagógica docente, como podemos verificar através das suas palavras no excerto a seguir.

A amorosidade da professora se expressava no querer bem às crianças e também no rigor na utilização do tempo e na organização das situações de aprendizagens. Exprimia alegria na forma cuidadosa como preparava, conduzia e vivenciava as atividades desenvolvidas. A amorosidade é um princípio que fundamentava as suas ações e contribuía para construir conhecimento e edificar relações sociais positivas. (GUEDES, 2015, p. 311).

Inscreve-se como atividade cotidiana a roda de conversa, atividade clássica na educação infantil para demarcar o início do tempo curricular no espaço de aprendizagem. No caso da pesquisa, a roda ganha configuração crítico-dialógica, realiza-se como situação de produção e socialização do conhecimento, a partir do reconhecimento das crianças como sujeitos críticos e criativos, capazes de partilhar saberes e experiências no e do espaço escolar e de outros espaços so- 
ciais. Ela pretende, assim, estimular "[...] a fala e a escuta; desenvolver atitudes e valores; trabalhar a oralidade e conteúdos curriculares; provocar nas crianças a curiosidade e o desejo de participar das atividades a serem realizadas durante a jornada”. (GUEDES, 2015, p. 283).

A intencionalidade educativa é construída pela pedagogia da pergunta (FREIRE; FAUNDEZ, 2002) que cumpre sua tarefa de explorar, articular, mobilizar falas, interesses e saberes. Desse modo, na roda, crianças e adultos se relacionam, ensaiam normas, atitudes e refletem coletivamente. Temas diversos emergem: gênero, localização geográfica, orientação de visitas culturais como conteúdos da leitura de mundo e reflexão coletiva.

Nessa vivência pedagógica, a valorização das experiências e dos saberes das crianças, o incentivo ao respeito e a valorização do outro se revelam, principalmente, através das brincadeiras de $f a z$ de conta, uma vez que elas propiciam "[...] as crianças se relacionarem uns com os outros, superando preconceitos e rejeição ao diferente". (GUEDES, 2015, p. 313).

A contação de história, no currículo da educação infantil, ocupa um lugar privilegiado e horários diversos na escola. Constitui oportunidade para exercer a criatividade e a criticidade, através de diferentes linguagens e gestos, ao mesmo tempo em que dá vida à escola e atrai crianças de outros grupos etários/turmas para participar das atividades.

Segundo Guedes (2015),

A contação de história demonstra a indissociabilidade entre a amorosidade e o processo educativo. É um momento de prazer que mobiliza, desperta a curiosidade e dá asas à imaginação, o que torna o espaço pedagógico um espaço onde se ensina e se aprende com alegria. (GUEDES, 2015, p. 288).

A essas duas atividades, que denotam a adesão aos referenciais freireanos e evidenciam a presença de relações dialógicas, juntam-se outras situações de produção do conhecimento organizadas pelas professoras que, igualmente, têm como princípios o desenvolvimento da criticidade e da criatividade, o respeito aos saberes e às experiências das crianças e o incentivo à fala e à escuta. (GUEDES, 2015, p. 309).

A pesquisa repertoriou jogos didáticos que trabalham conhecimentos de componentes curriculares, atividades de leitura com diferentes gêneros textuais, produção artística, além da feira de conhecimentos. Reconhece essas atividades como aquelas em que as crianças são chamadas a atuar como sujeito e o conhecimento como instrumento indispensável à compreensão da realidade, 
independente de faixa etária ou etapa da educação. Nesse sentido, o destaque à relação com o conhecimento e à finalidade que a ele se atribui vai ao encontro do que sustenta Paulo Freire, em texto publicado na obra "O Educador, vida e morte": “[...] a educação, não importando o grau em que ela se dá, é sempre uma certa teoria do conhecimento que se põe em prática". (FREIRE, 1985, p. 95).

A pesquisa, voltada para as práticas pedagógicas de valorização da identidade, da memória e da cultura negras (SILVA, 2016), também buscou no referencial freireano o horizonte da humanização. Neste sentido, o diálogo e, em decorrência, a reflexão serviram de lentes teóricas.

O campo empírico desta pesquisa foram instituições escolares que "[...] possuem origem na luta da sociedade, das comunidades, dos grupos sociais populares" (SILVA, 2016, p. 149), o que já declara sua implicação político-cultural. Nelas, há evidência de práticas dialógicas nas relações escola-comunidade; docente-docente; docente-discente; discente-discente; docente-conhecimento-discente, materializadas na articulação com equipamentos públicos ou comunitários, tais como o "[...] posto de saúde, o conselho tutelar, os centros comunitários, as associações de moradores..." (SILVA, 2016, p. 150). Portanto, há um movimento institucional, articulado, relacional e com intenção de trabalho com a diversidade e a diferença.

Nesse contexto, a pesquisa revelou, dentre seus achados, que a formação é "[...] uma importante estratégia para a construção, vivência e consolidação das práticas pedagógicas de valorização da identidade, da memória e da cultura negras". (SILVA, 2016, p. 158). Entretanto, não se trata de qualquer formação. Mas de uma formação crítica, reflexiva que contribua para o convencimento das implicações do racismo, da superação do silêncio dos sujeitos e da leitura crítica do lugar de subalternização do/da negro/a. O processo dialógico inscreve-se em um conjunto de situações de produção do conhecimento como formas de leitura e discussão da realidade - oficina temática, leitura de material de propagandas, confecção de cartazes - evidenciando o processo de problematização e a construção de sínteses, com o uso de diferentes linguagens, que deram origem a exposições do conhecimento produzido, fechando o ciclo do conhecimento.

A dimensão dialógica pode ser verificada na fala da pesquisadora quando testemunha que

O conjunto dos temas revela a ampliação do olhar para a cultura negra, até bem pouco tempo tratada apenas como religião, culinária e manifestação artística. Indica que existe um distanciamento da folclorização do mundo do povo negro, mostrando a possibilidade de enxergar mais que música, dança, comida e religião. Revela também a necessidade cons- 
tante de formação sobre a História da África, uma história ainda pouco conhecida e uma história que ainda é subtraída dos currículos escolares. (SILVA, 2016, p. 176).

A autora utiliza-se do construto teórico-metodológico ciclo de construção e vivência das práticas pedagógicas (SILVA, 2016, p. 119) para demonstrar a dinâmica da produção do conhecimento escolar como pluralidade e diversidade, sem desprezar a singularidade de sujeitos e de contextos e apontar práticas docentes-discentes reflexivas. Mostra os elementos que desenham a prática pedagógica institucional, a proposta pedagógica gerada na escola como tradução da intencionalidade do coletivo da escola e declara a horizontalidade das relações, a reflexão sobre a prática e os indícios da esperança nos sujeitos que trabalham e buscam a escola.

\section{À guisa de considerações finais}

Pesquisas em diversos domínios do campo da educação têm revelado a contribuição de Paulo Freire para a compreensão e a construção de políticas públicas em diferentes dimensões e etapas da educação básica. As pesquisas que foram objeto de análise mostram que tal contribuição se faz de forma inequívoca para os domínios da formação de professores e da prática pedagógica. O diálogo, nesses casos, é referenciado como fundamento da educação problematizadora e como atitude pedagógica docente. É uma contribuição para o trabalho na escola, desde que haja opção política por parte dos sujeitos da educação e a formação permanente contribua para uma outra educação escolar que tem início no momento mesmo em que professores/as se indagam e definem o quê e como trabalhar, a exemplo da elaboração e da discussão da agenda. Realiza-se como problematização das realidades em que vivem e educam crianças, jovens e adultos e se faz, também, como intervenção, a exemplo da carta escrita e encaminhada ao poder público municipal, citada por Leitão.

O diálogo, na perspectiva freireana, "[...] vai sendo concretizado enquanto intencionalidade, atitude de pessoas, opções e responsabilidades coletivas. Essa categoria mediatiza a relação sujeito-sujeito e sujeito-contexto". (SANTIAGO, 2006, p. 80-81). Nesse sentido, não se reduzirá à fala e à escuta, embora delas necessite, mas envolverá um intrincado processo que mobiliza sujeitos em relação com o mundo, consigo e com o outro, portanto, sujeitos em situação 
de construção de conhecimento, prática social necessária à vida e constitutiva de identidades individuais e sociais. O diálogo será, assim, exigente de um pensamento crítico-problematizador em relação ao qual as pesquisas fizeram prova. Essas mesmas pesquisas que, em suas démarches, reuniram elementos dos contextos estudados indiciários da importância da postura dialógica para a criação das condições para uma educação humanizadora, dentre as quais se destaca a disponibilidade curiosa à vida e a seus desafios.

Fato é que a instalação da prática do diálogo, como forma de mediação das relações no interior da escola e dos sistemas de ensino, coloca desafios de diferentes níveis e conteúdos. Sem observar ordem de prioridade, o desafio da formação do/da professor/a talvez seja um dos que ocupe uma certa centralidade neste debate. Uma formação que seja entendida não como capacitação ao uso de uma técnica ou de uma tecnologia de comunicação, mas que possibilite ao/à professor/a, refletindo sobre sua própria prática, compreender o sentido e o significado da dialogicidade. Uma formação que se negue a ser prescritiva e seja, ela mesma, dialógica. Uma formação que impulsione formador/a e formando/a a ousarem experimentar mudanças na relação docente-discente e que, para isso, exercitem a abertura de espírito de modo que seja possível a disponibilidade ao outro, em sua singularidade e diferença. Um diálogo que faça aprender a desaprender formas inibidoras da vivência democrática. Nesse sentido, um outro desafio é o da democracia, entendida como princípio mediador das relações entre sujeitos individuais e coletivos no interior da escola e dos sistemas de ensino. A democracia como modo de diálogo lastreado pelo respeito a distintas concepções e práticas educativas. A democracia como conteúdo do diálogo. O diálogo como condição da democracia.

\section{REFERÊNCIAS}

BRAGA, M. M. S. de C. Prática pedagógica docente-discente e humanização: contribuição de Paulo Freire para a escola pública. 241 f. Tese (Doutorado em Educação) - Centro de Educação, Universidade Federal de Pernambuco, Recife, 2012.

BRAGA, M. M. S. de C. Prática pedagógica docente-discente: traços da pedagogia de Paulo Freire na sala de aula. Recife: Editora UFPE, 2015.

FREIRE, P. Educação o sonho possível. In: BRANDÃO, C. R. (Org.). O Educador: vida e morte. 6. ed. Rio de Janeiro: Ed. Graal, 1985.

FREIRE, P. Pedagogia da Autonomia. São Paulo: Paz e Terra, 1997. 
FREIRE, P. A Educação na Cidade. 7. ed. São Paulo: Cortez, 2006.

FREIRE, P. Pedagogia do Oprimido. São Paulo: Paz e Terra, 2009.

FREIRE, P.; FAUNDEZ, A. Por uma pedagogia da pergunta. 5. ed. Rio de Janeiro: Paz e Terra, 2002.

GUEDES, M. G. de M. Contribuição de Paulo Freire para as políticas e práticas curriculares nos sistemas de ensino. 243 f. Tese (Doutorado em Educação) - Centro de Educação, Universidade Federal de Pernambuco, Recife, 2012.

GUEDES, M. G. de M. Princípios político-pedagógicos freireanos nas políticas curriculares e no chão da escola. Recife: Editora UFPE, 2015.

LEITÃO, E. S. S. A prática pedagógica docente na perspectiva da humanização em Paulo Freire na EJA de Olinda. 129 f. Dissertação (Mestrado em Educação) - Centro de Educação, Universidade Federal de Pernambuco, Recife, 2015.

SANTIAGO, E. Formação, currículo e prática pedagógica em Paulo Freire. In: BATISTA NETO, J.; SANTIAGO, E. (Org.). Formação de professores e prática pedagógica. Recife: Editora Massangana, 2006.

SILVA, C. M. da. Práticas pedagógicas de valorização da identidade, da memória e da cultura negras. 234 f. Tese (Doutorado em Educação) - Centro de Educação, Universidade Federal de Pernambuco, Recife, 2016.

SOUZA, J. F. de. Prática pedagógica e formação de professores. In: BATISTA NETO, J.; SANTIAGO, M. E. (Org.). Prática pedagógica e formação de professores. Recife: Editora UFPE, 2009.

Texto recebido em 16 de junho de 2016. Texto aprovado em 16 de junho de 2016. 
